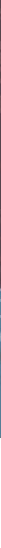

\title{
Who are the doctorate holders and where do their qualifications lead them?
}

- Many countries have implemented reforms to develop and support doctoral studies and postdoctoral research, stressing the crucial role of doctorate students and degree holders in terms of economic growth, innovation and scientific research.

- The number of advanced research qualifications being awarded across OECD countries significantly increased over the past decade, growing from 158000 new doctorates in 2000 to 247000 in 2012, a rise of $56 \%$. International students get one in five of these new doctorates.

- Even though the share of women in doctorate programmes has increased over the last decade (as in other levels of education), by $\mathbf{2 0 1 2}$ women were still less likely than men to earn an advanced research qualification.

- On average, individuals with advanced research qualifications benefit from higher employment rates compared to other university-level graduates (Bachelor's and Master's degrees combined).

- The business enterprise sector offers better wages for new doctorate holders than the higher education and government sectors, but also unequal opportunities, depending on the field in which they graduate.

Over just a couple of generations, our societies have evolved from a situation in which only an elite were highly educated to one in which close to $40 \%$ of $25-34$ year-olds hold a tertiary qualification. In a world where educational attainment is strongly associated with economic growth, the expansion of doctorate programmes is playing a crucial role in driving innovation and scientific research, while contributing to national and international knowledge bases.

OECD countries have invested heavily in doctorate programmes for the good of their economies. Supporting doctoral studies and postdoctoral research remains a priority for governments in many OECD countries, and also in non-OECD member countries such as China. Recent reforms in this area include:

- Expanding and improving public financial support for postgraduate studies. For instance, Australia has doubled the number of Australian Postgraduate Awards between 2008 and 2012.

- Developing postgraduate studies and support programmes with a view to attracting international talent. For example, Canada allocated USD 37 million (CAD 45 million) over five years (2010-15) to establish a prestigious postdoctoral programme and attract top-level talent to Canada.

- Supporting the transition of doctorate holders into the private sector through programmes that widen their skills (for instance, including courses on elementary management and business finance).

As a consequence, the number of doctorate holders significantly increased over the past decade. Although doctorate programmes represent a small proportion of all tertiary programmes, on average across OECD countries $1.6 \%$ of young people in 2012 are expected to graduate from these programmes over their lifetimes, compared with only $1.0 \%$ in 2000 . 
The doctoral level is level 8 in the International Standard Classification of Education (ISCED-2011). It leads directly to the award of an advanced research qualification, e.g. a PhD. In most countries, the theoretical duration of these programmes is three years full time (leading to a cumulative total of at least seven years of full-time equivalent tertiary education), although the actual enrolment time is typically longer. Programmes at this ISCED level are devoted to advanced studies and original research and are typically offered by research-oriented tertiary educational institutions such as universities. Doctoral programmes exist in both academic and professional fields.

In 2012, the largest share of new doctorate holders was in science (24\%), followed by social sciences, business and law (21\%). Science and engineering degrees together account for $40 \%$ of new doctorate holders and social $6 \%$ sciences and humanities for $34 \%$. There are significant variations among countries in the share of new science and engineering degrees. Science accounts for more than 30\% of new advanced research qualifications in Chile, Estonia, France, Iceland and Israel, and even more than 50\% in Luxembourg. Engineering represents more than $20 \%$ of new advanced research programmes in the Czech Republic, Denmark, Finland, Germany, Korea and the Slovak Republic.

More women and more international students are earning advanced research qualifications.

Even though the share of women in doctorate programmes has grown over the last decade, they are still less likely than men to earn an advanced research qualification. In 2012, on average across OECD countries, women received $46 \%$ of advanced research degrees, up from 38\% in 2000. However, there are wide differences between countries. Women now earn more than half of advanced research qualifications in around one-quarter of OECD countries, namely Australia, Brazil, Estonia, Finland, Israel, Italy, Latvia, New Zealand, Poland, Portugal, Slovenia and the United States. In Japan and Korea, only about $30 \%$ of advanced research qualifications are awarded to women (see Figure 1).

Figure 1. Graduation rates at doctoral level and percentage of doctorate degrees awarded to women $(2000,2012)$

\begin{tabular}{|c|c|c|c|c|c|c|c|c|c|c|c|c|c|c|c|c|c|c|c|c|c|c|c|c|c|c|c|c|c|c|c|c|c|c|c|c|c|c|c|}
\hline $\begin{array}{c}\% \\
4.0 \\
\end{array}$ & & & & & & & & & & & & & & & & -20 & 012 & & $>$ & 200 & & & & & & & & & & & & & & & & & & & \\
\hline 3.5 & & & & & & & & & & & & & & & & & & & & & & & & & & & & & & & & & & & & & & & \\
\hline 3.0 & & & & & & & & rce & nta & ge o & $\mathrm{f} \mathrm{do}$ & م & rate & de & gree & & & & & & & & & & & & & & & & & & & & & & & & \\
\hline 2.5 & $\begin{array}{ll}46: \\
\square\end{array}$ & 45 & 51 & 49 & 46 & & & varc & & to $y$ & vom & & & & & & & & & & & & & & & & & & & & & & & & & & & & \\
\hline 2.0 & & & & & & & 42 & 48 & 50 & 45 & 49 & & & & & & & & & & & & & & & & & & & & & & & & & & & & \\
\hline 1.5 & & & & & & & & & & & & & & & & & & 46 & 41 & 33 & 52 & 53 & & & & & & & & & & & & & & & & & \\
\hline 1.0 & & & & & & 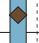 & & & & & & & & & & & & & & & & & & & & 44 & $\begin{array}{l}51 \\
\end{array}$ & 60 & & & & & & & & & & & \\
\hline 0.5 & & & & 1) & & & & & & & & & & & & & & & & & & & & & & & & & & & & & 51 & & & & & & \\
\hline 0.0 & & & & & & & & & & & & & & & & & & & & & & & & & & & & & & & & & & & & $\square^{39}$ & 42 & 45 & $\begin{array}{l}40 \\
\end{array}$ \\
\hline $\begin{array}{l}\widetilde{D} \\
\mathbb{Z} \\
\mathbb{Z} \\
\mathbb{d} \\
N\end{array}$ & 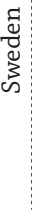 & 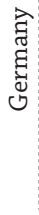 & 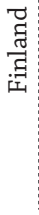 & 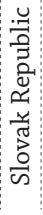 & 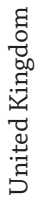 & 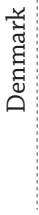 & $\frac{\pi}{\underset{Z}{4}}$ & $\begin{array}{l}\text { ते } \\
3 \\
0 \\
2\end{array}$ & 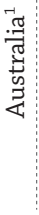 & 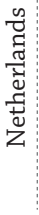 & 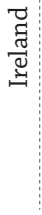 & $\begin{array}{l}7 \\
0 \\
\Xi \\
己 \\
0 \\
0 \\
.\end{array}$ & $\begin{array}{l}\widetilde{J} \\
\mathbb{J} \\
\widetilde{J} \\
\mathrm{~N} \\
3 \\
\mathrm{~J}\end{array}$ & $\begin{array}{l}\frac{\sigma}{\vec{J}} \\
0 \\
0 \\
0 \\
\omega\end{array}$ & 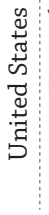 & 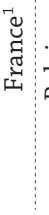 & 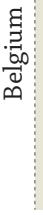 & 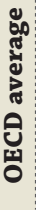 & 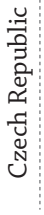 & $\begin{array}{l}\tilde{J} \\
0 \\
0 \\
x\end{array}$ & $\begin{array}{l}\vec{\varpi} \\
\underset{\tilde{w}}{\omega} \\
\bullet\end{array}$ & 夰 & $\begin{array}{l}\pi \\
\widetilde{J} \\
\widetilde{J}\end{array}$ & 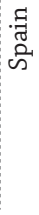 & 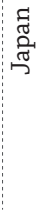 & 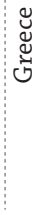 & 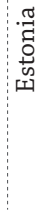 & 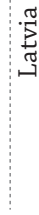 & 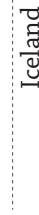 & 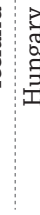 & $\begin{array}{lll} & 0 \\
0 & 0 \\
0 & 0\end{array}$ & ટ్ & 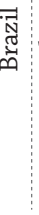 & 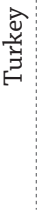 & 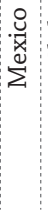 & 光 & 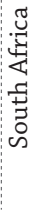 & 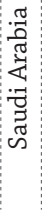 & 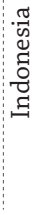 \\
\hline
\end{tabular}

1. Year of reference 2011.

Countries are ranked in descending order of the graduation rates in 2012.

Source: OECD (2014), Education at a Glance 2014: OECD Indicators, Indicator A3 (www.oecd.org/edu/eag.htm). 
Highlighting the competition for talent between countries, international students are now more likely to graduate at the highest levels of education than in the past, reflecting an increasing internationalisation of academic research and science in OECD countries. Globally, among OECD countries, around one in five tertiary students graduating from doctorate programmes in 2012 was an international student. The proportion exceeded 29\% in Australia, Belgium, France, Iceland, the Netherlands, New Zealand, Switzerland and the United Kingdom, raising the issue of the dependence of university research laboratories on the international talent pool in some countries.

\section{On average, individuals with advanced research qualifications benefit from higher employment rates.}

Unexpectedly, even in times of economic downturn, the average employment rate among doctoral graduates remains high compared to other university-level graduates: 91\% compared with 85\% for those with Bachelor's and Master's degrees. The difference is particularly marked in Estonia, Greece, Hungary and Spain, where it exceeds 10 percentage points (see Figure 2).

Figure 2. Employment rates of 25-64 year-olds, by educational attainment (2012)

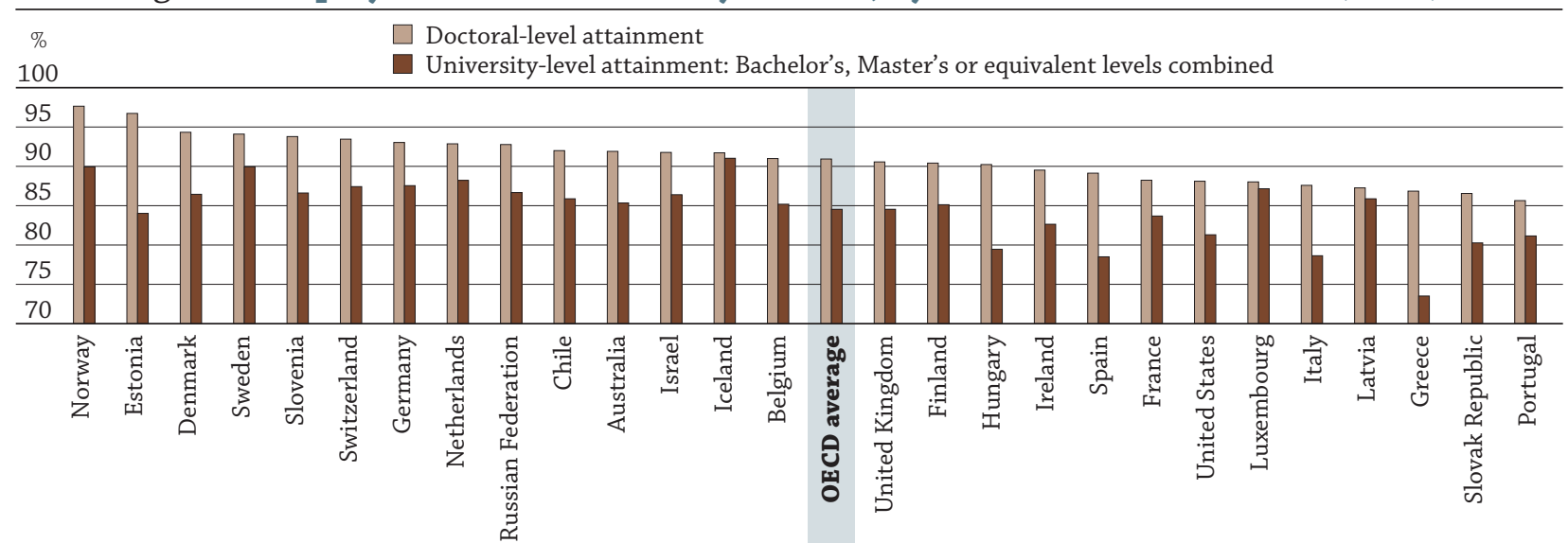

Countries are ranked in descending order of the employment rates of 25-64 year-olds who have attainted the doctoral level. Source: OECD Education Database.

Figure 3. Doctorate holders by sector of employment, 2009

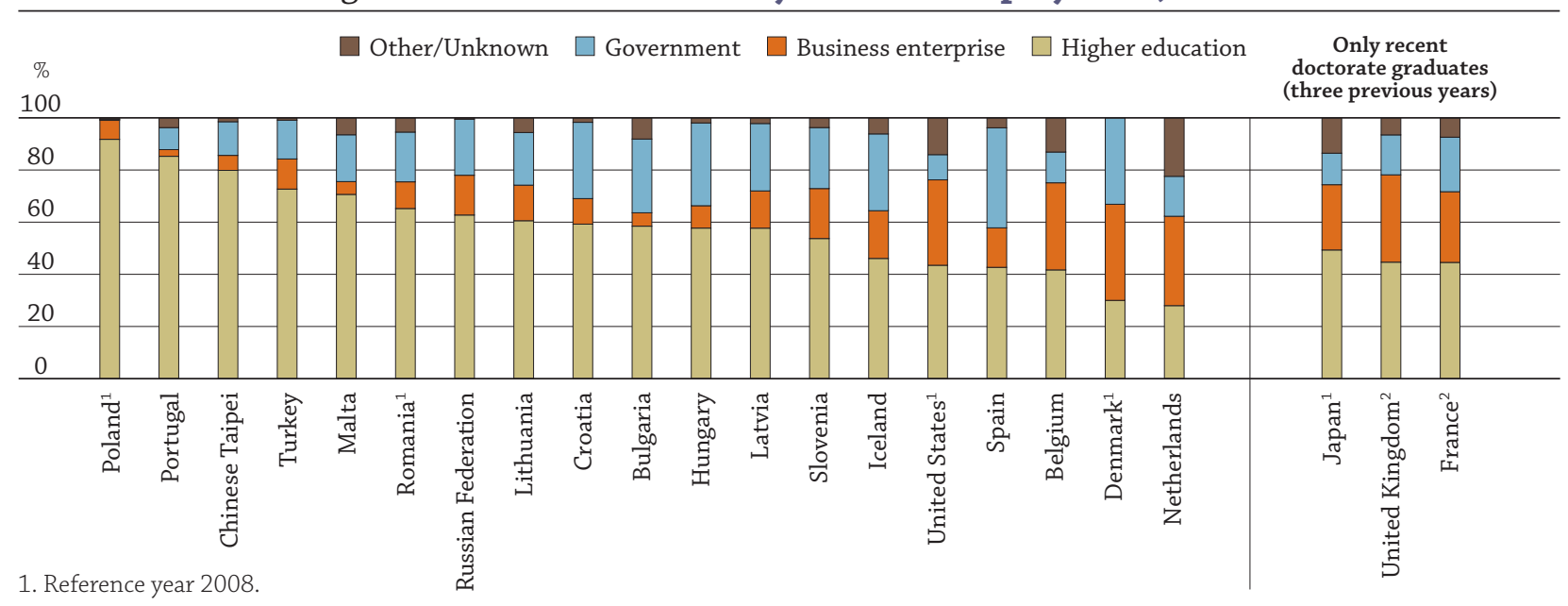

2. Reference year 2010.

Countries are ranked in descending order of doctorate holders working in the higher education sector.

Source: OECD (2013), OECD Science, Technology and Industry Scoreboard 2013. 


\section{EDUCATION INDICATORS IN FOCUS}

education data education evidence education policy education analysis education statistics

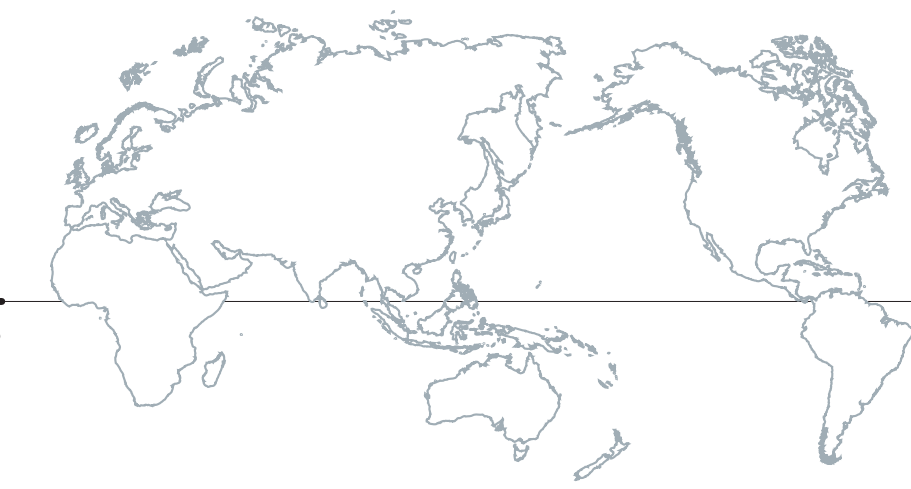

Moreover, although female and younger doctorate holders fare relatively worse in terms of employment rates than their older and male counterparts, these biases are less marked for doctorate holders than for individuals with lower levels of educational attainment. These results should be interpreted with some caution, however, the employment benefit could be smaller or negative if doctorate holders are compared only with Master's degree holders and analysed by field of education.

\section{The higher education sector dominates doctorate holders'careers but they are better paid in the enterprise sector. \\ The OECD Careers of Doctorate Holders' project demonstrates that in many OECD countries, over $60 \%$ of doctorate holders work as researchers. While higher education is the main employment sector for individuals with a doctorate, in some countries such as Belgium, Denmark, France, Japan, the United Kingdom and the United States, doctorate holders are becoming more prevalent in enterprises, with around one-third of them employed in the business sector (see Figure 3).}

As one might expect, doctorate holders are typically better paid in the business sector than in academia. The gap is nearly $25 \%$ for the United States, a country where academic pay is considered to be high. Moreover, there are significant earning variations across subject areas, partly reflecting differing labour market demands for different specialised skills and knowledge. For instance, earnings in agricultural sciences and the humanities are below the overall median in most countries, whereas doctorate holders in medical and health sciences tend to be paid above that level.

The bottom line: There have been many recent initiatives to support and develop doctorate programmes, as these qualifications are among the main drivers of innovation, economic growth and scientific research. As a consequence, the past decade has witnessed a steady increase in the number of doctoral degrees being awarded across OECD countries. Nowadays individuals with advanced research qualifications benefit from higher employment rates compared to other university-level graduates, even if job opportunities vary from one field of study to the next.

\section{For more information}

OECD (2014), Education at a Glance 2014: OECD Indicators, OECD Publishing, Paris, http://dx.doi.org/10.1787/eag-2014-en.

OECD (2013), OECD Science, Technology and Industry Scoreboard 2013, OECD Publishing, Paris, http://dx.doi.org/10.1787/sti_scoreboard-2013-en. OECD, "Strengthening education for innovation", Science, Technology and Innovation Policy Profiles: Human Resources, see www.oecd.org/sti/outlook/ e-outlook/stipolicyprofiles/humanresources/strengtheningeducationforinnovation.htm.

OECD Science, Technology and Industry/UNESCO Institute for Statistics/Eurostat (2013), Careers of Doctorate Holders (CDH) project, see www.oecd.org/sti/cdh.

UNESCO Institute for Statistics (2011), International Standard Classification of Education (ISCED), UNESCO, www.uis.unesco.org/Education/ Documents/isced-2011-en.pdf.

\section{Contact}

Eric Charbonnier (Eric.Charbonnier@oecd.org) / Joris Ranchin (Joris.Ranchin@oecd.org) / Laudeline Auriol (Laudeline.Auriol@oecd.org)

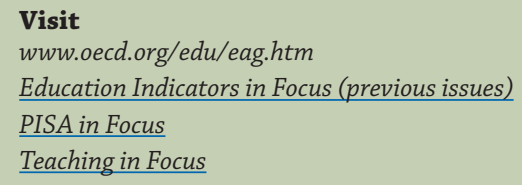

\section{Coming next month}

Learning Beyond Initial Education: To What Extent do Adults Participate in Education?

Photo credit: @ Ghislain \& Marie David de Lossy/Cultura/Getty Images

This paper is published under the responsibility of the Secretary-General of the OECD. The opinions expressed and arguments employed herein do not necessarily reflect the official views of OECD member countries.

This document and any map included herein are without prejudice to the status of or sovereignty over any territory, to the delimitation of international frontiers and boundaries and to the name of any territory, city or area.

The statistical data for Israel are supplied by and under the responsibility of the relevant Israeli authorities. The use of such data by the OECD is without prejudice to the status of the Golan Heights, East Jerusalem and Israeli settlements in the West Bank under the terms of international law. 